Esta revista forma parte del acervo de la Biblioteca Jurídica Virtual del Instituto de Investigaciones Jurídicas de la UNAM

\title{
Aspectos transfronterizos de la gestación por sustitución
}

\section{Cross-Border Aspects of Substitute Gestation}

\author{
Nuria GONZÁLEZ MARTÍN* \\ María Mercedes Albornoz**
}

SUMARIO: I. Introducción. II. La gestación por sustitución: diversidad y contexto. III. Filiación: algunas cuestiones de derecho internacional privado. IV. Gestación por sustitución transfronteriza: estatus jurídico de los niños y de los padres intencionales. V. De cara al futuro. VI. Bibliografía.

* Doctora en Derecho Internacional Privado, Universidad Pablo de Olavide, Sevilla. LLM (DEA) en Derecho, Universidad de Sevilla. Investigadora en el Instituto de Investigaciones Jurídicas de la UNAM.

** Doctora y LLM (DEA) en Derecho Internacional Privado, Université de Paris II. Profesora investigadora en el CIDE.

Artículo recibido el 18 de mayo de 2015

Aprobado para publicación el 31 de agosto de 2015 
RESUMEN: El artículo trata el tema de la gestación por sustitución y aborda parte de la compleja problemática que surge a raíz de la misma, especialmente cuando se está ante una gestación por sustitución transfronteriza. Se aproxima a la diversidad del fenómeno y lo contextualiza. Asimismo, analiza algunas cuestiones de derecho internacional privado de la filiación y luego se concentra en el estatus jurídico de los niños que nacen como consecuencia de acuerdos de gestación por sustitución transfronteriza con respecto a sus padres intencionales. Finalmente, de cara al futuro, destaca la necesidad de un instrumento internacional sobre gestación por sustitución transfronteriza.

Palabras clave: gestación por sustitución, maternidad subrogada, gestación por sustitución transfronteriza, filiación, técnicas de reproducción asistida, Derecho Internacional Privado, Conferencia de La Haya de Derecho Internacional Privado

ABSTRACT: This article deals with the topic of substitue gestation and addresses some of the complex problems that arise from it, especially when the substitute gestation is a cross-border one. It approaches the diversity of the phenomenon and contextualizes it. Moreover, it analyzes some other issues of Private International Law of Parentage and then it focuses on the legal status of children who are born following international surrogacy arrangements vis-à-vis their intended parents. Finally, looking forward, the article highlights the need for an international instrument on cross-border surrogacy.

Key words: Substitute Gestation, Surrogate Motherhood, Cross-border Gestation, Crossborder Surrogacy, International Surrogacy Arrangements, Parentage, Assisted Reproduction Techniques, Private International Law, Hague Conference on Private International Law

RÉSumÉ: Cet article traite le sujet de la gestation par substitution et il aborde une partie des problèmes complexes découlant de ce type de gestation, en particulier lorsqu'on est en présence d'une gestation par substitution transfrontalière. Il envisage la diversité du phénomène et il le contextualise. Également, il analise certaines questions de Droit International Privé de la filiation et ensuite il se concentre sur le status juridique des enfants qui naissent suite à des accords de gestation par substitution transfrontalière. Finalement, pour l'avenir, il souligne le besoin d'un instrument international portant sur la gestation par substitution transfrontalière. Mots-clé: gestation par substitution, maternité de substitution, gestation par substitution transfrontalière, filiation, techniques de réproduction assistée, Droit International Privé, Conférence de La Haye de Droit International Privé 


\section{INTRODUCCIÓN}

En la actualidad hay un aumento de la presencia de la denominada familia internacional, es decir, aquellas familias conformadas por individuos que están bajo la jurisdicción de naciones diversas; igualmente hay un aumento de las llamadas nuevas estructuras familiares ante la proliferación de familias ensambladas, monoparentales, homoparentales, y así un largo etcétera. En consecuencia, se torna imperiosa la necesidad de ampliar la noción de familia por canales y conductos diversos a los de la concepción tradicional.

Podemos presentar a una familia que ante la decisión de incrementar sus miembros y ante frecuentes cruces de frontera, junto con el desarrollo de la medicina, proyecta una serie de actividades que pueden quedar lejos incluso de una regulación doméstica o nacional.

Nos encontramos ante un nuevo paradigma familiar y la presencia de diferentes técnicas de reproducción humana asistida, que proporcionan un hijo a aquella familia ávida del mismo y que, por diversos motivos, han decidido no procrear de manera natural por sí mismas. "Se habla de «revolución reproductiva» porque estas técnicas separan la reproducción humana de la sexualidad". ${ }^{1}$ De hecho, en este contexto la opción de la gestación subrogada o por sustitución (en adelante GS) se está desarrollando de manera vertiginosa, ${ }^{2} \sin$ una regulación o con una regulación en ocasiones confusa e incompleta. ${ }^{3}$ Estas lagunas normativas o incoherencias legislativas fomen-

1 Lamm, Eleonora, Gestación por sustitución. Ni maternidad subrogada ni alquiler de vientres. Barcelona, Universidad de Barcelona, 2013, p. 17.

2 En Estados Unidos, sin embargo, la GS se ha empezado a desarrollar hace aproximadamente treinta años. Holt, Kyle Lee, "Hoosier Mother?: Indiana's Inconsistent Surrogacy Law”, Valparaíso University Law Review, núm. 48, 2014, p. 1139. El movimiento en torno a la GS inició en 1985/6 con el famoso caso estadounidense Baby M. In re Baby M, 537 A.2d 1227 (N.J. 1988). Para una reseña y análisis dicho movimiento, véase Spivack, Carla, "The Law of Surrogate Motherhood in the United States", American Journal of Comparative Law, núm. 58, 2010, pp. 99 y ss., y Peng, Lina, "Surrogate Mothers: An Exploration of the Empirical and the Normative", American University Journal of Gender, Social Policy \&The Law, núm. 21, 2013, passim.

3 Como lo señala Ingrid Brena Sesma refiriéndose a México: "La falta de legislación sobre el tema es preocupante, pero una normativa inadecuada lo es aún más". "La maternidad subrogada ¿es suficiente la legislación civil vigente para regularla?”, Revista de Derecho Priva- 
Esta revista forma parte del acervo de la Biblioteca Jurídica Virtual del Instituto de Investigaciones Jurídicas de la UNAM www.juridicas.unam.mx

tan el surgimiento de oportunidades de negocio lucrativo, que directa o indirectamente afectan a un número importante de niños, madres y padres. ${ }^{4}$ En definitiva, estamos ante la presencia de una nueva concepción de la familia, de un cruce transfronterizo y ante un "turismo reproductivo" en donde el punto de mira se debe focalizar en los derechos de los niños nacidos mediante esta práctica, derechos de los niños a que se respete su interés superior. ${ }^{6}$

Este artículo se enfocará en la problemática que surge a raíz de la gestación por sustitución transfronteriza (en adelante GST). El fenómeno de la GS, que se encuadra dentro de las técnicas de reproducción asistida, ${ }^{7}$ ha recibido distintas denominaciones, tales como "maternidad subrogada", "maternidad sustituta", "maternidad por sustitución”, "alquiler de vientre", "gestación por sustitución”. Entendemos que "gestación por sustitución” se adecua mejor al fenómeno regulado, ${ }^{8}$ dado que no pone el acento en la maternidad - lo que implicaría dejar en un segundo plano la pater-

do, núm. 23, 2009, http://biblio.juridicas.unam.mx/revista/pdf/DerechoPrivado/1/dtr/dtr7.pdf (último acceso: 11 de mayo de 2015) p. 142. La misma autora destaca la necesidad de que la autoridad pública intervenga en esta área para garantizar los derechos de los sujetos involucrados. "La gestación subrogada. ¿Una nueva figura del derecho de familia?”, en Brena Sesma, Ingrid (coord.), Reproducción asistida, México, UNAM, Instituto de Investigaciones Jurídicas, 2012, http://biblio.juridicas.unam.mx/libros/7/3155/10.pdf (último acceso: 11 de mayo de 2015), p. 160.

4 International Social Services. Boletín Mensual, Número Especial "Gestación subrogada de carácter internacional y derechos del niño”, núm. 174, julio-agosto de 2013. www.iss-ssi. org (último acceso: 11 de mayo de 2015).

5 Acerca de este fenómeno y las preocupaciones que genera, véase Lamm, E., op. cit., pp. 193 y ss.

6 Observación General núm.14 del Comité de los Derechos del Niños sobre el derecho del niño a que su interés superior sea una consideración primordial. Aprobado por el Comité el 29 de mayo de 2013. El Comité establece que el interés superior del niño debe ser el factor determinante, es decir, no simplemente "una consideración primordial" sino "la consideración primordial”. http: / /www2.ohchr.org/english (último acceso: 11 de mayo de 2015).

7 Véase Méndez Zambrano, Maritza, "La reproducción asistida”, en Guerra Hernández, Víctor Hugo et al. (coord.), Derecho familiar internacional. Metodología para su estudio. Homenaje a Haydée Barrios, Medellín, Biblioteca Jurídica Diké-Universidad del Rosario, 2014, pp. 745 778.

8 De manera coincidente, Eleonora Lamm ha titulado su libro: "Gestación por sustitución. Ni maternidad subrogada ni alquiler de vientres". Esta autora define la GS como "una forma de reporducción asistida, por medio de la cual una persona, denominada gestante, acuerda con otra persona, o con una pareja, denominadas comitente, gestar un embrión con el fin de 
Esta revista forma parte del acervo de la Biblioteca Jurídica Virtual del Instituto de Investigaciones Jurídicas de la UNAM

nidad — sino en la actividad o fin principal perseguido por las partes de la relación jurídica: la gestación.

A los fines de conceptualizar específicamente la GST, elegimos adoptar la definición con la que trabaja la Conferencia de La Haya de Derecho Internacional Privado (en adelante, Conferencia de La Haya o Conferencia), a pesar de que dicho organismo se refiere a la GS como "acuerdo de maternidad de sustitución" o "acuerdo de maternidad subrogada". En este sentido, la GST es aquélla que surge como consecuencia de un acuerdo "celebrado entre uno o dos padres intencionales que residen en un Estado y una madre portadora que reside en otro Estado (o que tan solo se encuentra allí)" ${ }^{9}$ Este tipo de acuerdo puede implicar donantes de gametos en el Estado de residencia de la madre portadora (o aquél donde ella se encuentra) o incluso en un tercer Estado y, asimismo, consistir en un acuerdo de procreación por otro o de gestación por otro, que en ambos casos podrán ser a título oneroso o a título gratuito. ${ }^{10}$

En el acuerdo de procreación por otro, la madre portadora provee su propio material genético (óvulo), con la lógica consecuencia de que el niño tendrá un vínculo genético con ella. En el marco de estos acuerdos puede haber concepción natural o recurrirse a técnicas de reproducción humana asistida. En cambio, en el acuerdo de gestación por otro, la madre portadora no provee su propio material genético. Generalmente, los acuerdos de gestación por otro son precedidos por un tratamiento de reproducción humana asistida. Y los gametos pueden pertenecer a uno o a ambos padres de intención, o no provenir de ninguno de ellos. ${ }^{11}$

Ante todo, será necesario aproximarnos a la diversidad del fenómeno de la GS así como al contexto en el que se presenta (II). Como el tema se enmarca dentro del área más general de las relaciones de filiación, se con-

que la persona nacida tenga vínculos jurídicos de filiación con la parte comitente”. Op. cit., p. 24.

9 Es en estos términos que la Conferencia de La Haya define los acuerdos internacionales de maternidad de sustitución: Conférence de La Haye de Droit International Privé, Affaires Générales et Politique, Opportunité et possibilité de poursuivre les travaux menés dans le cadre du projet filiation / maternité de substitution, Doc prél. $N^{\circ} 3 \mathrm{~B}$, Annexe A - Glossaire mis à jour, abril 2014, http: / / www.hcch.net/index_fr.php?act=text.display\&tid=178 (último acceso: 11 de mayo de 2015), p. i.

10 Idem.

11 Idem. 
Esta revista forma parte del acervo de la Biblioteca Jurídica Virtual del Instituto de Investigaciones Jurídicas de la UNAM www.juridicas.unam. $\mathrm{mx}$

tinuará con el análisis de algunas cuestiones jurídicas de la filiación transfronteriza (III). Posteriormente, abordaremos el estatus jurídico de los niños y de los padres intencionales en casos de GST (IV), antes de extraer algunas conclusiones de cara al futuro $(\mathrm{V})$.

\section{LA GESTACIÓN POR SUSTITUCIÓN: DIVERSIDAD Y CONTEXTO}

Para comprender a carta cabal el complejo fenómeno de la GS, destacaremos su diversidad (1) y el contexto en el que se presenta (2).

\section{Diversidad}

La GS origina una situación realmente delicada en la que se presenta un panorama muy variado, en función de: ${ }^{12}$

- Los sujetos que desean tener un hijo mediante GS (uno o varios, solteros o casados, parejas del mismo o de distinto sexo);

- Las motivaciones que llevaron a la GS (infertilidad, ${ }^{13}$ incapacidad para procrear por parte de parejas del mismo sexo, temor a dar a luz, peligro a la hora de dar a luz, decisión de no pasar por el proceso de embarazo y, por qué no, aquellas personas que ante la imposibilidad - jurídica o práctica — de adoptar, optan por la maternidad subrogada y a través de esta ficción consiguen su fin último: ampliar su familia y, si es necesario en función del derecho del Estado receptor, consolidar su vínculo jurídico con el niño a través de la adopción)..$^{14}$

12 González Martín, Nuria, "Maternidad subrogada y adopción internacional”, en Brena Sesma, I. (coord.), op. cit., http: / /biblio.juridicas.

13 La Organización Mundial de la Salud concibe la infertilidad como una enfermedad y un problema de salud mundial, http://www.who.int/reproductivehealth/topics/infertility/defini tions/en/ (último acceso: 11 de mayo de 2015).

14 Podemos y debemos pensar no sólo en la adopción por parte de parejas o matrimonios heterosexuales sino también en las parejas o matrimonios homosexuales y en personas solteras, sean cuales sean sus preferencias sexuales. 
Esta revista forma parte del acervo de la Biblioteca Jurídica Virtual del Instituto de Investigaciones Jurídicas de la UNAM

- Los medios para la consecución de la paternidad/maternidad ${ }^{15}$ (paternidad genética o social: gametos masculinos del varón o de uno de los varones de la pareja de padres intencionales, o gametos aportados por un tercero; maternidad genética o jurídica/social-: alquiler de útero, cuando la mujer gestante o portadora recibe el embrión, o madre biológica si además aporta su óvulo, o el supuesto en el que una mujer aporte su óvulo, otra geste y una tercera asuma la responsabilidad parental, siendo esta última la madre jurídica o social). ${ }^{16}$

- El fin que se busca (lucro o gratuidad). ${ }^{17}$

15 Paternidad/maternidad no son sinónimos de procreación.

16 La maternidad subrogada puede presentar una serie de modalidades:

"Subrogación total. Implica que la mujer contratada sea inseminada con sus propios óvulos, y que después de la gestación y el parto entregue el hijo al padre biológico, renuncie a todos sus derechos que la maternidad le genera y admita la adopción de la pareja del padre biológico en relación con la maternidad del menor."

1) "Subrogación parcial. Esta se da cuando la gestadora es contratada exclusivamente para portar en su vientre un embrión fecundado in vitro que le ha sido transplantado, pero que proviene de la unión de espermatozoide y óvulo de la pareja contratante.”

2) "Subrogación comercial. Se da cuando una mujer acepta embarazarse por otra, tal y como si se tratase de un servicio, por el cual se paga una cantidad cierta y determinada, además de los gastos de la gestación.”

3) "Subrogación altruista. Se da cuando una mujer acepta gestar un hijo por cuenta de otra de manera gratuita, generalmente por mediar entre ella y la pareja implicada un lazo de amor, amistad o parentesco.”

Rodríguez López, Dina, "Nuevas técnicas de reproducción humana. El útero como objeto del contrato”, Revista de Derecho Privado. Nueva Serie, núm. 11, mayo-agosto de 2005, http: / / www.juridicas. unam. $\mathrm{mx} /$ publica/rev/derpriv/cont/11/dtr/dtr5.htm (último acceso: 11 de mayo de 2015), pp. 109 y 110.

El tema presenta una gran variedad de aristas. Para explorarlas en el ámbito del derecho civil, véanse los textos de Clavería Gonzálbez. Por ejemplo: Clavería Gonzálbez, Luís Humberto, "Las categorías negociales y su adaptación en función de la reproducción”, La filiación a finales del S. XX: problemática planteada por los avances científicos en materia de reproducción humana, Madrid, Trivium, 1988.

17 En realidad, la madre portadora es quien tiene o no un fin de lucro. El tema de la finalidad que la madre gestante persigue es delicado, ya que generalmente se acepta que se le dé dinero para garantizar que esté bien alimentada y médicamente cuidada durante el embarazo. ¿Se podría considerar que tal pago implica lucro? Creemos que, en principio, no. ¿Pero dónde estaría el límite...? La Conferencia de La Haya reconoce que a veces es difícil distinguir los acuerdos altruistas de los acuerdos con fines de lucro. Véase: Conférence de La Haye, Opportunité et possibilité..., loc. cit. 
Esta revista forma parte del acervo de la Biblioteca Jurídica Virtual del Instituto de Investigaciones Jurídicas de la UNAM www.juridicas.unam. $\mathrm{mx}$

En cuanto a la regulación de la GS a nivel internacional, nos encontramos ante una laguna normativa ${ }^{18}$ que es necesario llenar, a fin de evitar o al menos reducir la gran cantidad de problemas derivados de la diversidad de las normas de fuente interna en derecho comparado. En efecto, tal como lo plantea Nieve Rubaja, "la gestación por sustitución (GS) se presenta como una realidad que supera las previsiones de muchos de los ordenamientos jurídicos y trae como resultado diferentes tintes problemáticos". ${ }^{19}$

En este sentido, resulta muy delicada la situación en la que puede encontrarse la madre que alquiló su vientre para llevar a cabo una GS, especialmente cuando el derecho del Estado donde está domiciliada, no contiene normas que resguarden sus derechos humanos. ${ }^{20}$ Asimismo, es fuente de preocupación la gran incertidumbre que existe acerca de cuestiones esenciales atinentes a los niños que nacen como consecuencia de una GS. De acuerdo con Rubaja, "la GS — ya sea con material genético aportado por uno o ambos comitentes o por la propia gestante o incluso de terceros - tiene una variada recepción por parte de los distintos ordenamientos jurídicos. ${ }^{21}$

Mientras las normas de derecho interno de algunos países expresamente rechazan o prohíben estas prácticas, ${ }^{22}$ las de otros no regulan específica-

18 Ninguno de los instrumentos internacionales que existen en la actualidad contiene normas específicas para regular la GST. Trimmings, Katarina y Beaumont, Paul, "International Surrogacy Arrangements: an Urgent Need for Legal Regulation at the International Level”, Journal of Private International Law, vol. 7, núm. 3, 2011, p. 630.

19 Rubaja, Nieve, "El derecho internacional privado al servicio de los derechos fundamentales de los niños nacidos por el empleo de la gestación por sustitución en el extranjero”, Moreno Rodríguez, José Antonio y Lima Marques, Claudia (coords.), Los servicios en el derecho internacional privado. Jornadas de la ASADIP 2014, Porto Alegre, Gráfica Editora, 2014, pp. 281 y ss.

20 Es lo que, según Caroline Vincent y Alene D. Aftandilian, sucede en la India, uno de los típicos Estados de nacimiento en casos de gestación por sustitución transfronteriza. Vincent y Aftandilian, "Liberation or Exploitation: Commercial Surrogacy and the Indian Surrogate", Suffolk Transnational Law Review, núm 36, 2013, pp. 671-682.

21 Rubaja, N., loc. cit.

22 Es, por ejemplo, el caso de Francia. Véase la respuesta de Francia a la pregunta 24 del Questionnaire on the Private International Law Issues Surrounding the Status of Children, including Issues arising from International Surrogacy Arrangements, http://www.hcch.net/upload/wop/gap2014pd3fr.pdf (último acceso: 11 de mayo de 2015). Acerca de los intentos (hasta ahora frustrados) de establecer una regulación del tema en Francia, véase: Petitfils, Charlotte y Muñoz Sastre, María Teresa, "French Layperson's Views on Surrogate Motherhood: an Exploratory Study”, Psicológica, núm. 35, 2014, pp. 694 y 695. 
Esta revista forma parte del acervo de la Biblioteca Jurídica Virtual del Instituto de Investigaciones Jurídicas de la UNAM

mente esta materia. ${ }^{23}$ Asimismo, en algunos países se prohíbe expresamente que el acuerdo de maternidad subrogada tenga un fin de lucro (es decir, que haya un pago a la madre portadora superior a los gastos que ésta deba soportar como consecuencia del acuerdo). ${ }^{24} \mathrm{~A}$ su vez, entre las legislaciones que reciben la GS, los requisitos establecidos son diferentes y también lo son las consecuencias además de la utilización de estas técnicas. ${ }^{25}$ En los Estados federales, los estados que los componen tienen facultades para regular la GS: aquí también existen diferencias de una entidad federativa a otra, dentro del mismo país. ${ }^{26}$ Todas estas circunstancias favorecen el turis-

23 Es, por ejemplo, el caso de Colombia. Véase la respuesta de Colombia a la pregunta 24 del Questionnaire on the Private International Law Issues..., http: / /www.hcch.net/upload/wop / gap2014pd3co.pdf (último acceso: 11 de mayo de 2015). Nótese que, como lo recuerdan Camilo A. Rodríguez-Yong y Karol Ximena Martínez-Muñoz, en Colombia no hay regulación del tema, a pesar de que en 2009 la Corte Constitucional reconoció la necesidad de contar con regulación (T-968/09). "El contrato de maternidad subrogada: la experiencia estadounidense”, Revista de Derecho (Valdivia), vol. XXXV, núm. 2, 2012, p. 62.

24 Es el caso de Australia, Nueva Zelanda y Reino Unido, entre otros países. Conférence de La Haye de Droit International Privé, Affaires Générales et Politique, Étude sur la filiation juridique et questions découlant des conventions de maternité de substitution à caractère international, Doc. Prél. núm. 3C (L'Étude), marzo de 2014, disponible en http: / /www.hcch. net/upload/wop/gap2015pd03c_fr.pdf (último acceso: 11/05/2015), p. 16, nota 113. Con respecto a Reino Unido, que cuenta con la Surrogacy Arrangements Act desde 1985, el país "ha venido manteniendo una actitud prohibitiva con respecto a la práctica comercial de la gestación por sustitución, prohibiendo el contrato y penalizando la actividad comercial (los intermediarios y la publicidad), pero admite la gestación por sustitución a título benévolo y sin intermediarios". Lamm, Eleonora, "Gestación por sustitución”, InDret Revista para el Análisis del Derecho, núm. 3, 2012, http://www.indret.com/pdf/909_es.pdf (último acceso: 11 de mayo de 2015), p. 15.

25 Rubaja, N., loc. cit. nota 19.

26 Es, por ejemplo, el caso de México y de Estados Unidos de América. Dentro de la República Mexicana, hay solo dos estados que permiten expresamente la maternidad sustituta o GS. Ellos son Tabasco (artículo 92 del Código Civil) y Sinaloa (artículos 283 y ss. del Código Familiar). Asimismo, en el estado de Coahuila "el contrato de maternidad subrogada es inexistente" (artículo 491 del Código Civil del Estado de Coahuila). En cuanto a los proyectos legislativos que hubo en otras entidades federativas, véase: Rodríguez Martínez, Eli, "Los Contratos Internacionales sobre Maternidad subrogada. Un vistazo rápido al Derecho Comparado", Revista Derecho en Libertad, núm. 13, 2014, http: / / www.fldm.edu.mx / pdf/revista / no13/Derecho13-Arti11.pdf (último acceso: 11 de mayo de 2015), p. 156. Dentro de Estados Unidos, varios estados declaran nulos y no ejecutables los acuerdos de GS: Arizona, Indiana, Michigan, Nueva York y Washington DC. Un buen número de Estados regulan, con diferencias entre sí, la GS: Arkansas, Florida, Illinois, Nevada, Nuevo Hampshire, Dakota del Norte, 
Esta revista forma parte del acervo de la Biblioteca Jurídica Virtual del Instituto de Investigaciones Jurídicas de la UNAM

mo reproductivo como una suerte de forum shopping de los padres intencionales, que se desplazan cruzando fronteras en busca de un país amigable con respecto a la GS. ${ }^{27}$

Cuando la GS presenta aspectos transfronterizos, es decir, tiene puntos de conexión con al menos dos sistemas jurídicos diferentes, estamos ante una "gestación por sustitución transfronteriza" y entran en juego las normas de derecho internacional privado en materia de filiación.

\section{Contexto}

En efecto, la GS es un fenómeno que en la actualidad existe en diversos países y que debe ser encuadrada en un contexto más amplio: el de la filiación.

La Conferencia de La Haya de Derecho Internacional Privado (en adelante, Conferencia de La Haya o la Conferencia), ya en 2011 señalaba que la gestación por sustitución transfronteriza constituía un "comercio mundial en pleno auge”. Y que, por entonces, no había plena conciencia de los desafíos jurídicos que generaba, sobre todo en lo atinente al estatus jurídico de los niños. En la actualidad, cuatro años después, se puede afirmar sin temor a equivocarse que el tema despierta gran interés y preocupación a nivel internacional. Y no sólo eso, sino que dada la gravedad acuciante de la problemática generada en torno a la gestación por otro, se la considera un tema prioritario en el seno de instituciones internacionales. Por ejemplo, el Comité de las Naciones Unidas de los Derechos del Niño ha discutido el tema en 2013 y en 2014. A su vez, la Conferencia de La Haya cuenta con un "Proyecto sobre filiación y maternidad por sustitución", cuya culminación ideal sería la elaboración de un instrumento internacional que contribuya a solucionar los inconvenientes prácticos que se suscitan en casos de gestación por sustitución transfronteriza.

Tennessee, Texas, Utah, Virginia y Washington. Otros Estados no tienen legislación sobre GS, pero la jurisprudencia la admite: California y Connecticut. En Minesota todavía no hay precedentes obligatorios. Gruenbaum, Daniel, "Foreign Surrogate Motherhood: mater semper certa erat”, American Journal of Comparative Law, vol. 60, 2012, pp. 486-488.

27 "La variedad de respuestas nacionales a la subrogación ha llevado a un extendido forum shopping mediante el cual parejas infértiles que desean tener un niño a través de la subrogación, viajan de un país a otro buscando deliberadamente como destino jurisdicciones 'amigables con la subrogación'” (la traducción es nuestra). Trimmings, K. y Beaumont, P., op. cit., p. 629. 
Resulta difícil la tarea de obtener datos oficiales acerca de la gestación por sustitución transfronteriza. Es por eso que, tal como lo señala el Estudio sobre la filiación jurídica y cuestiones derivadas de los acuerdos de maternidad por sustitución con carácter internacional elaborado en 2014 por la Conferencia de La Haya ${ }^{28}$ no se cuenta con una fotografía completa pero sí con “instantáneas" ${ }^{9}$ acerca de este tipo de acuerdos de gestación en el mundo.

El fenómeno ha crecido exponencialmente en los últimos años, tanto en número de casos como en alcance territorial.

En lo atinente al número de casos, a modo de ejemplo, las 19 respuestas de abogados de diversos países al cuestionario diseñado por la Conferencia dan cuenta de que el número de casos en los cuales estos profesionales del derecho intervinieron pasó de 26 en 2008, a 328 en 2012. Nótese que esto implica un aumento del $1162 \%$ en tan solo cinco años.

Si bien una GST puede estar vinculada con más de dos Estados, tiene que haber al menos dos y se los denomina "Estado de nacimiento" y "Estado de recepción”. Los Estados de nacimiento con mayor número de casos son, por mucho, Estados Unidos e India. Seguidos luego por países como Tailandia, Ucrania, Rusia, Georgia y Canadá y, en menor medida, por Australia, China, Grecia, Israel, México, entre otros. Los Estados de recepción se localizan en los cinco continentes. Sólo mencionaremos algunos: África del Sur, Alemania, Argentina, Australia, Bélgica, Brasil, Canadá, Chile, China, Colombia, Costa Rica, Egipto, Emiratos Árabes Unidos, Ecuador, España, Estados Unidos — tómese en cuenta que en países como Ucrania, por ejemplo, la gestación por sustitución es más económica que en Estados Unidos-- Japón, México, Nepal, Nueva Zelanda, Países Bajos, Reino Unido, Senegal, Singapur, Suiza, Turquía, Uruguay, Venezuela...

Un dato interesante es el hecho de que las madres portadoras no suelen desplazarse de su país de residencia a otro, a efectos de dar a luz en el extranjero. Generalmente, quienes se desplazan al país de la madre portadora son los padres de intención. Son ellos también los que, una vez nacido el niño, lo conducen al extranjero.

28 Conférence de La Haye, Étude sur la filiation juridique..., cit. nota 24.

29 Ibidem, p. 60, párrafo 124. 
Esta revista forma parte del acervo de la Biblioteca Jurídica Virtual del Instituto de Investigaciones Jurídicas de la UNAM

\section{FiliaCiÓN: ALGUNAS CUESTIONES}

DE DERECHO INTERNACIONAL PRIVADO

Dado que la GS se encuadra dentro del tema de la filiación, es importante recordar algunas cuestiones de Derecho Internacional Privado que, por consiguiente, sirven también para resolver problemas planteados por la GST. Si bien en casos transfronterizos la filiación puede llegar a ser establecida de nuevo en el Estado de recepción, en muchas ocasiones se procede al reconocimiento de la filiación establecida en el extranjero. Haremos algunas consideraciones en torno a este último supuesto (1). También nos ocuparemos de la competencia internacional directa para impugnar la filiación (2), antes de detenernos en cuestiones de ley aplicable a la filiación y a su impugnación (3) y a los efectos jurídicos del reconocimiento de la filiación (4).

\section{Reconocimiento de la filiación establecida en el extranjero}

Para reconocer en un determinado Estado la filiación establecida en el extranjero, es necesario contar con un documento expedido por el Estado extranjero del que se trate. La naturaleza de ese documento extranjero puede ser: acta de nacimiento, reconocimiento voluntario o sentencia. ${ }^{30}$

Ahora bien, el reconocimiento voluntario generalmente estará plasmado en el acta de nacimiento. Tanto el acta de nacimiento como la sentencia extranjera (y la carta rogatoria que acompaña a esta última) deben ser documentos auténticos. Por consiguiente, deben haber sido legalizados o $\operatorname{apostillados}^{31}$. Asimismo, en caso de ser necesaria la traducción, ésta debería estar certificada por un perito traductor oficial.

En lo atinente al reconocimiento del acta de nacimiento, los Estados establecen distintas pautas. Algunos la reconocerán si se ajusta a ciertas condiciones procesales. Otros, si es válida según la ley aplicable en virtud del

30 Ibidem, p. 43, párrafo 84.

31 Convenio que suprime la exigencia de legalización de los documentos públicos extranjeros, La Haya, 5 de octubre de 1961. Texto, estado actual e información adicional, disponibles en http: / /www.hcch.net/index_es.php?act=conventions.text\&cid=41 (último acceso: 11 de mayo de 2015). 
derecho internacional privado del Estado receptor, que en ciertos países implica siempre una remisión a la lex fori. En algunos Estados receptores, a pesar de la existencia de un acta de nacimiento extranjera, la filiación se determina nuevamente de conformidad con la ley designada por la norma de conflicto de dichos Estados. También hay Estados receptores que pueden tomar en cuenta el acta, siempre que ésta constituya un acto público válido en el Estado de origen. ${ }^{32}$

El Estado receptor está facultado a denegar el reconocimiento si hay una violación de su orden público (internacional). En algunos países está prevista también la denegación de reconocimiento del acta de nacimiento extranjera si se detecta que hubo fraude a la ley.

Si el documento probatorio de la filiación establecida en el extranjero es una sentencia, su reconocimiento se encuadra dentro del régimen general de reconocimiento de sentencias extranjeras. Recuérdese que un punto crucial del control a efectuar en el Estado receptor es la conformidad con el orden público (internacional) de dicho Estado.

\section{Competencia internacional directa para impugnación de la filiación}

En la mayoría de los Estados, la competencia internacional directa en materia de impugnación de la filiación corresponde a las autoridades judiciales. Excepcionalmente, en algunos países la impugnación también puede ventilarse ante autoridades administrativas. ${ }^{33}$

Las normas de competencia internacional varían sustancialmente de un Estado a otro. Hay Estados en los cuales se aplican las normas generales de competencia para asuntos civiles. En algunos Estados se aplican normas de competencia internacional para asuntos del estado civil de las personas naturales. Y hay ciertos Estados que cuentan con normas específicas para la impugnación de la filiación. ${ }^{34}$

32 Conférence de La Haye, Étude sur la filiation juridique..., cit., pp. 44 y 45, párrafo 86.

33 Por ejemplo, en Alemania, la impugnación puede hacerse en sede judicial o ante las autoridades del estado civil. Respuesta de Alemania a la pregunta 31 del Questionnaire on the Private International Law Issues..., http: / / www.hcch.net/upload/wop/gap2014pd3de.pdf (último acceso: 11 de mayo de 2015).

34 Conférence de La Haye, Étude sur la filiation juridique..., cit., p. 51, párrafo 103. 
Esta revista forma parte del acervo de la Biblioteca Jurídica Virtual del Instituto de Investigaciones Jurídicas de la UNAM

También hay diversidad en los puntos de conexión escogidos por dichas normas. Encontramos normas que determinan un punto de conexión único; pero también normas con puntos de conexión múltiples, que pueden relacionarse entre sí de manera alternativa o subsidiaria.

Entre el amplio abanico de puntos de conexión de las normas que determinan la competencia internacional directa para impugnar la filiación, encontramos: la residencia habitual del niño (en ocasiones, condicionada a que el nacimiento haya sido registrado en ese Estado); la nacionalidad del niño; la residencia habitual o la nacionalidad de un padre putativo que impugna la filiación, o de un padre putativo contra quien se entabla la acción; el domicilio del niño o de uno de sus padres; el Estado de nacimiento del niño; la residencia habitual o el domicilio del demandado; la residencia de la madre; una "conexión importante" probada con el Estado del foro. ${ }^{35}$

\section{Ley aplicable a la filiación y a su impugnación}

Encontramos dos grandes tendencias en cuanto a la determinación de la ley aplicable a la filiación y a su impugnación. Por un lado, hay Estados cuyas normas de conflicto permiten eventualmente aplicar un derecho extranjero y Estados que sistemáticamente aplican la lex fori. Por otro lado, en muchos de los Estados donde es posible aplicar derecho extranjero a la filiación y a su impugnación, el punto de conexión esencial es la nacionalidad (generalmente del niño, aunque también la de los padres putativos). En otros Estados, sin embargo, hay varios puntos de conexión posibles y la elección entre ellos se funda en el interés superior del menor. ${ }^{36}$

En México, ante la ausencia de normas de conflicto específicas para filiación, se recurre a las que regulan el estado civil. ${ }^{37}$ Y según cuál sea el código de fondo aplicable, el estado civil se regirá por la ley del domicilio del hijo (de acuerdo con el principio favor filii), o bien por la lex fori.

35 Ibidem, pp. 51 y 52, párrafo 103.

36 Ibidem, pp. 41 y 42 , párrafo 80.

37 Véase Pereznieto Castro, Leonel y Silva Silva, Jorge Alberto, Derecho internacional privado. Parte especial, 2a. ed., México, Oxford University Press, 2007, p. 254. 
4. Ley aplicable a los efectos jurídicos del reconocimiento de la filiación

En la mayoría de los Estados, la ley que rige los efectos jurídicos del reconocimiento de la filiación es, como sucede en México, la lex fori. No obstante, hay Estados que disponen de una norma de conflicto especial para los efectos de la filiación jurídica (sometiéndolos, por ejemplo, al derecho del domicilio del niño). En otros Estados, si bien no existe una norma especial para tales efectos, hay una norma de conflicto general que determina la ley aplicable a la filiación jurídica y es esa norma la que se empleará. ${ }^{38}$

IV. GESTACIÓN POR SUSTITUCIÓN TRANSFRONTERIZA: ESTATUS JURÍDICO DE LOS NIÑOS Y DE LOS PADRES INTENCIONALES

En muchos casos de gestación por sustitución, la filiación de los niños es diferente según la ley de distintos Estados, lo que convierte el estatus de hijo en una "filiación claudicante", válida en algunos países y no reconocida en otros.

Esto puede suceder a raíz de un conflicto entre las perspectivas o enfoques adoptados por el derecho internacional privado del Estado de nacimiento del niño que fue alumbrado como consecuencia de una GST, y el derecho internacional privado del Estado de recepción, donde el niño residirá o ya reside. ${ }^{39}$ Las normas sobre filiación y nacionalidad o estatus migratorio del menor de cada uno de esos Estados pueden conducir a soluciones divergentes, con el resultado de que el niño e incluso sus padres intencionales quedarán prácticamente "atrapados" en una maraña normativa. En efecto, quienes han nacido como consecuencia de un acuerdo de GST pueden verse perjudicados en cuanto a su filiación y adquisición de nacionalidad. ${ }^{40}$

Veamos a continuación cuáles son las principales perspectivas acerca de la referida problemática, en los Estados de nacimiento (1) y en los Estados de recepción (2).

38 Ibidem, p. 53, párrafo 106.

39 Ibidem, p. 70, párrafo 148.

40 Rubaja, N., op. cit., pp. 281 y ss. 
Esta revista forma parte del acervo de la Biblioteca Jurídica Virtual del Instituto de Investigaciones Jurídicas de la UNAM

\section{Estados de nacimiento}

En los Estados de nacimiento donde es más común realizar acuerdos de GS, suele haber procedimientos para atribuir la filiación jurídica a los padres intencionales. ${ }^{41}$ Dicha atribución puede tener lugar después del nacimiento, como sucede en Rusia, en Ucrania o en la India, o incluso antes de que el niño haya nacido, como es el caso de California, en Estados Unidos de América. Adoptando una perspectiva más general con respecto a los diferentes estados de Estados Unidos, la doctrina ha identificado como una estrategia creciente de las partes, la solicitud a un tribunal de una declaración de paternidad ${ }^{42}$ antes de que la madre portadora dé a luz. ${ }^{43}$ Algunos tribunales han hecho lugar a tales solicitudes; pero otros no. ${ }^{44}$

A efectos de la determinación de la competencia para registrar al recién nacido, el hecho de que su nacimiento se haya producido en el territorio del Estado es un factor de conexión relevante. Es decir, las autoridades del Estado de nacimiento son las competentes para registrarlo.

En una gran cantidad de Estados se aplica la lex fori para determinar la filiación, incluso si los padres intencionales del menor residen en el extranjero. Diferente y llamativo es el caso de la India, donde se exige que para realizar allí una GST, los padres intencionales obtengan previamente una visa médica.Y a efectos de que tal visa les sea concedida por las autoridades indias, los padres intencionales deben demostrar que su Estado acepta la GS y que ellos podrán llevar al niño a ese Estado. ${ }^{45}$

Con respecto a la nacionalidad, el niño nacido luego de una GST, en general no adquirirá la nacionalidad del Estado de nacimiento. ${ }^{46}$ No obstante, la regla es diferente en algunos países como Canadá y Estados Unidos. Esto significa que, por ejemplo, en uno de los frecuentes casos de GST en California, donde reside la madre portadora y nace el niño, con padres intencionales extranjeros, el menor contará con la nacionalidad estadounidense.

41 Conférence de La Haye, Étude sur la filiation juridique..., cit., p. 70, párrafo 149.

42 Aclaramos que aquí se utiliza el término "paternidad" en sentido amplio, incluyendo también la maternidad.

43 Spivack, C., op. cit., p. 107.

44 Idem. Allí se puede consultar algunos ejemplos de varios estados.

45 Conférence de La Haye, Étude sur la filiation juridique..., cit., p. 71, párrafo 149.

46 Esto se debe al "hecho de que los padres intencionales sean determinados padres jurídicos del niño, asociado a la ausencia de una norma absoluta de ius soli que permita la adquisición de la nacionalidad" (la traducción es nuestra). Conférence de La Haye, Étude sur la filiation juridique..., cit., p. 71, párrafo 150. 


\section{Estados de recepción}

En los casos de GST, el menor nacido en un Estado será trasladado al Estado donde residirá, que generalmente será el país donde los padres intencionales tienen su centro de vida. Ahora bien, es de suma importancia que éstos se informen acerca de los requisitos migratorios del Estado de recepción antes de abandonar con el niño el Estado de nacimiento, a fin de evitar que el menor sea retenido en la frontera y se le impida ingresar al Estado de destino. Y tener en cuenta que no es lo mismo que el menor ingrese al Estado de recepción como extranjero (si adquirió la nacionalidad y obtuvo del Estado de nacimiento algún documento oficial que le permita viajar al extranjero) o que lo haga como nacional (si adquirió y obtuvo de la representación consular del Estado de recepción algún documento oficial que lo faculte a ingresar al territorio de dicho Estado).

En Estados federales la nacionalidad es cuestión federal, en tanto que la filiación y el registro de nacimientos competen a los estados o entidades federativas (es lo que ocurre en Australia, Estados Unidos, México), ${ }^{47}$ o provincias (en el caso de Canadá). ${ }^{48}$ En consecuencia, se produce una disociación de competencias, ${ }^{49}$ que podría tener por efecto que el Estado de recepción reconociera o estableciera la filiación del niño nacido en el extranjero luego de una GST y que, sin embargo, no le confiriera su nacionalidad. $\mathrm{O}$, a la inversa, es posible que el niño adquiera la nacionalidad del Estado de recepción, sin que se reconozca ni se establezca su filiación con respecto a uno o ambos padres intencionales. Así, por ejemplo, en casos entrantes en Estados Unidos, para que el niño nacido en el extranjero como consecuencia de una GS pueda adquirir la nacionalidad estadounidense, debe haber un lazo genético con un nacional de este país norteamericano. ${ }^{50}$ ¿Qué sucedería si de una pareja binacional residente en Estados Unidos, en la que

47 Hemos incluido a México en este grupo, a pesar de que no figura entre los Estados federales mencionados en la sección pertinente del Estudio de la Conferencia. Ibidem, p. 73, párrafo 155 .

48 Idem, p. 73, párrafo 155.

49 Nótese que la disociación de competencias está directamente relacionada con el régimen federal, más que con la tradición jurídica a la que pertenece el Estado de recepción en cuestión.

50 En los demás Estados federales mencionados en este párrafo, la atribución de la nacionalidad del Estado de recepción al niño nacido en el extranjero luego de una GST no depende 
Esta revista forma parte del acervo de la Biblioteca Jurídica Virtual del Instituto de Investigaciones Jurídicas de la UNAM

sólo la madre fuese estadounidense, naciera un niño luego de una GST con donación de óvulos? En este supuesto no existiría un lazo genético con la madre estadounidense. Un caso similar fue resuelto en el sentido de que el niño adquirió la nacionalidad del padre intencional; pero necesita visa para residir en el Estado receptor, Estados Unidos. ${ }^{51}$

El tratamiento de las consecuencias jurídicas derivadas de la GST varía de un país a otro y de jurisdicciones internas a tribunales supranacionales. Sin embargo, es posible encontrar algunos trazos comunes entre países que pertenecen a una misma tradición jurídica.

Una vez que el menor nacido luego de una GST se encuentra en el Estado de residencia habitual de sus padres intencionales, generalmente surgen dificultades cuando se intenta registrar la partida de nacimiento otorgada en el extranjero. En la práctica, hay una gran variedad de casos. En algunos de ellos se ha determinado la filiación de cero en el Estado de recepción; en otros, se ha procedido a reconocer la sentencia extranjera que establece el vínculo filiatorio, o bien a inscribir en el registro civil del Estado de recepción el acta de nacimiento expedida en el extranjero. ${ }^{52}$

En esta sección presentaremos los criterios que con respecto al estatus jurídico de los niños y de los padres intencionales han venido adoptando los países de Common Law (A), los países de tradición civilista (B) y el Tribunal Europeo de Derechos Humanos (C).

\section{A. Criterios de países de common law}

Los países que siguen la tradición jurídica del common law pueden ser divididos en dos grupos. ${ }^{53}$ En el primero encontramos aquellos Estados donde, en virtud del régimen federal adoptado, se produce la disociación de competencias en materia de nacionalidad por un lado, y de filiación y registro

exclusivamente de la existencia de un vínculo genético con un nacional. Conférence de La Haye, Étude sur la filiation juridique..., cit., p. 74, párrafo 159.

51 Ibídem, pp. 74 y 75, párrafo 159.

52 Rubaja, N., op. cit., pp. 281 y ss.

53 División sugerida en el estudio realizado por la Conferencia de La Haya. Conférence de La Haye, Étude sur la filiation juridique..., cit., pp. 73-76, párrafos 155 y ss. Si bien podría interpretarse que el estudio considera el grupo de países federales como un sub-grupo de los países de common law, nosotros hemos incluido a México (país de tradición civilista) entre los Estados federales. Véase supra, nota 47. 
de nacimientos por el otro. ${ }^{54}$ Pertenecen a este grupo Australia, Canadá, Estados Unidos. En el segundo grupo, en el cual encontramos por ejemplo a Irlanda, Nueva Zelanda y Reino Unido, todo lo atinente al estatus jurídico de los niños nacidos en el extranjero luego de una GS se determina de conformidad con las normas de derecho interno. ${ }^{55}$

En otras palabras, en los países de common law pertenecientes al segundo grupo, la pregunta de quiénes son los padres jurídicos del menor se responde mediante la aplicación de la lex fori del Estado de recepción. De modo que el niño podrá adquirir de pleno derecho la nacionalidad del Estado de recepción, siempre que el derecho interno de ese Estado determine que, en el caso concreto, el menor tiene un padre jurídico nacional del mismo. ${ }^{56}$

En algunos de esos Estados, si la madre portadora fuese soltera, el padre intencional nacional del Estado de recepción y vinculado genéticamente con el menor podría ser considerado padre jurídico del niño según el derecho interno del Estado de recepción. ${ }^{57}$ En otros, los padres intencionales nunca llegarán a ser considerados padres jurídicos en virtud del derecho interno. Entonces, la salida al problema filiatorio consiste en transferir la filiación a uno o ambos padres intencionales, ${ }^{58} \mathrm{o}$ bien en llevar a cabo una adopción (o dos adopciones) conforme al derecho interno del Estado de recepción, una vez que el niño nacido en el marco de un acuerdo de GST se encuentre en el territorio de dicho Estado. ${ }^{59} \mathrm{Y}$ generalmente el menor adquirirá por la nacionalidad de ese Estado en virtud del nuevo estado filiatorio.

\section{B. Criterios de países de tradición civilista}

Aunque muchos de los Estados de recepción pertenecientes a la tradición romano-germánica deciden si un niño puede adquirir su nacionalidad de pleno derecho por filiación verificando si el menor tiene un padre jurídico

54 Véase lo expuesto cuatro párrafos más arriba.

55 Conférence de La Haye, Étude sur la filiation juridique..., cit., p. 75, párrafo 160.

56 Idem.

57 Es el caso de Irlanda y de Reino Unido. Idem, especialmente nota 622.

58 Allí donde la transferencia de filiación está permitida como, por ejemplo, en Reino Unido. Conférence de La Haye, Étude sur la filiation juridique..., cit., p. 75, párrafo 161, especialmente nota 625 .

59 Ibidem, p. 75, párrafo 161. 
Esta revista forma parte del acervo de la Biblioteca Jurídica Virtual del Instituto de Investigaciones Jurídicas de la UNAM

nacional de ese Estado, en buena parte de ellos la filiación no se determinará aplicando las normas de derecho interno, sino las normas de derecho internacional privado de ese Estado. ${ }^{60}$ Se advierte claramente aquí una diferencia con los países de common law a los que nos hemos referido más arriba. ${ }^{61}$

Sin embargo, lejos estamos de presenciar un panorama de cierta uniformidad en cuanto al derecho internacional privado de estos países civilistas: hay divergencias de contenido que pueden incluso llevar a la adopción de abordajes del tema totalmente distintos ${ }^{62}$. Por ejemplo, desde el empleo del método de reconocimiento para un acta de nacimiento expedida en el extranjero, hasta el establecimiento de la filiación jurídica de novo en el Estado de recepción, según el derecho designado por sus normas de conflicto $^{63}$. Dadas estas divergencias, y siguiendo el Estudio realizado por la Conferencia de La Haya, veremos algunas tendencias que ya es posible identificar en los países de tradición romano-germánica.

Una tendencia que se aprecia, verbi gratia, en Bélgica, España y Países Bajos, consiste en permitir que la paternidad jurídica de un padre intencional (generalmente con un vínculo genético con el niño) sea reconocida o bien establecida nuevamente en el Estado receptor. No obstante, la filiación con respecto a la madre o al segundo padre intencionales, deberá establecerse mediante adopción. Un problema adicional dentro de este enfoque es el hecho de que algunos Estados prohíben la adopción de un menor nacido como consecuencia de una GS si esta última tuvo fines de lucro, o si los padres intencionales no están casados o si son del mismo sexo. ${ }^{64}$

Entre los diversos y complejos casos que la Conferencia de La Haya ha elegido para abordar la problemática del estatus jurídico de los hijos en los Estados de recepción civilistas, haremos mención de algunos aspectos en torno al tema en Países Bajos y en España. Asimismo, agregaremos una breve referencia a un reciente caso alemán ${ }^{65}$ que avanza un paso más allá

$60 \quad$ Ibidem, p. 76, párrafo 163.

61 Véase supra, IV, 2, A.

62 Conférence de La Haye, Étude sur la filiation juridique..., cit., p. 76, párrafo 163.

63 Ídem, especialmente nota 631.

64 Conférence de La Haye, Étude sur la filiation juridique..., cit., p. 80, párrafo 166.

65 Tribunal Federal alemán, sentencia del 10 de diciembre de 2014. Resumen y comentario en inglés en: Reis, Dina, "German Federal Court of Justice on Surrogacy and German Public Policy”, posteado por Jan Von Hein en el blog Conflictoflaws.net, 4 de marzo de 2015, 
Esta revista forma parte del acervo de la Biblioteca Jurídica Virtual del Instituto de Investigaciones Jurídicas de la UNAM

con respecto a esta tendencia, porque en el caso concreto se ha reconocido el estatus filiatorio del menor con respecto a dos padres intencionales, sin que fuera necesario recurrir a la adopción para el segundo de ellos.

En Países Bajos, a menudo se rechaza el reconocimiento de actas de nacimiento extranjeras por razones de orden público. El rechazo no se funda en que la GS sea en sí misma violatoria del orden público holandés, sino en que éste se ve vulnerado por el hecho de que el acta de nacimiento extranjera no mencione madre alguna, o porque la que allí figure como madre no sea la madre portadora, la que dio a luz. ${ }^{66}$

En España, mediante una decisión reciente, ${ }^{67}$ el Tribunal Supremo negó el registro de actas de nacimiento californianas correspondientes a unos menores nacidos luego de una GST, en las que figuraban como padres dos padres intencionales varones, nacionales y residentes en España. Consideró que las actas eran contrarias al orden público internacional español y que integra el mismo el artículo 10 de la Ley 14/2006 de Técnicas de Reproducción Humana Asistida. ${ }^{68}$ Entendió que había que tomar en cuenta el interés superior del menor; pero que debía ponderárselo "con los demás bienes jurídicos concurrentes, como son el respeto a la dignidad e integridad moral de la mujer gestante, evitar la explotación del estado de necesidad en el que pueden encontrarse mujeres jóvenes en situación de pobreza, o impedir la mercantilización de la gestación y de la filiación” ${ }^{69} \mathrm{La}$

http: / / conflictoflaws.net/2015/german-federal-court-of-justice-on-surrogacy-and-german-publicpolicy/ (último acceso: 11 de mayo de 2015).

66 Conférence de La Haye, Étude sur la filiation juridique..., cit., p. 77, párrafo 164, 2. Por ejemplo: Rechtbank 's-Gravenhague, 23 de noviembre de 2009, 14 de septiembre de 2009 y 24 de octubre de 2011, citados por la Conferencia de La Haya en la nota 639.

67 Tribunal Supremo, Pleno, Sentencia núm. 835/2013, 6 de febrero de 2014, http:// www.poderjudicial.es/cgpj / es / Poder-Judicial / Tribunal-Supremo /Jurisprudencia / Actualidad-Juris prudencial / TS-Civil-Pleno--Desestima-recurso-de-casacion--Gestacion-por-sustitucion--Inscripcionen-el-Registro-Civil-espanol-de-la-filiacion-de-unos-menores-nacidos-tras-la-celebracion-de-un-con trato-de-gestacion-por-sustitucion-a-favor-de-los-padres-intencionales-determinada-por-las-autori dades-de-California-con-base-en-la-legislacion-de-dicho-estado- (último acceso: 11 de mayo de 2015).

68 Artículo 10. "Gestación por sustitución. 1. Será nulo de pleno derecho el contrato por el que se convenga la gestación, con o sin precio, a cargo de una mujer que renuncia a la filiación materna a favor del contratante o de un tercero. 2. La filiación nacido por gestación de sustitución sera determinada por el parto. 3. Queda a salvo la posible acción de reclamación de la paternidad respecto del padre biológico, conforme a las reglas generales."

69 Tribunal Supremo, sentencia núm. 835/2013, cit. nota 67. 
Esta revista forma parte del acervo de la Biblioteca Jurídica Virtual del Instituto de Investigaciones Jurídicas de la UNAM

mayoría (por cinco votos contra cuatro) decidió conferirles mayor peso a estos últimos intereses del Estado. La disidencia, en cambio, destacó que el orden público debe valorarse caso por caso y negó aquí la existencia de una vulneración del orden público internacional español. Asimismo, pugnaba por que se distinguiese la ilegalidad de la GS en España, del reconocimiento de efectos a una GS extranjera.

En la sentencia alemana a la que aludíamos más arriba ${ }^{70}$ el Tribunal Federal de ese país tenía que decidir si, a pesar de la prohibición interna de la GS, se reconocería o no en Alemania una sentencia californiana que confería la paternidad de un niño nacido como consecuencia de una GS a dos varones, padres intencionales. La madre gestante era una estadounidense soltera. El óvulo se obtuvo de una donante anónima. El esperma utilizado para la inseminación artificial pertenecía a uno de los padres intencionales. Ambos padres intencionales eran alemanes residentes en Alemania y estaban vinculados entre sí mediante una unión civil registrada. El Tribunal Federal decidió que no se podía negar el reconocimiento de la sentencia extranjera invocando violación del orden público. Por consiguiente, ordenó a la oficina del registro civil proceder a registrar el nacimiento del niño figurando los padres intencionales como padres jurídicos. El tribunal consideró que el orden público alemán no se veía conculcado por el simple hecho de que en un caso de GST, la paternidad jurídica fuera atribuida a los padres intencionales, dado que uno de ellos tenía un vínculo biológico con el niño, mientras que la madre portadora no tenía relación biológica alguna con el menor.

Otra tendencia más liberal reconoce el estatus jurídico de la madre intencional en los acuerdos de GS. ${ }^{71}$ Se funda en el interés superior del menor y en las consecuencias que para el menor tendría el no reconocimiento de su relación de filiación con la madre intencional.

En esta línea, en una decisión del 14 de diciembre de 2011, la Corte Constitucional de Austria resolvió un caso sobre adquisición de la nacionalidad austríaca por parte de un menor, por filiación. ${ }^{72}$ Nótese que tal adquisición estaba condicionada a que al menos un padre jurídico fuera austríaco. La corte se apoyó en una sentencia estadounidense para acordar la nacio-

70 Véase nota 65.

71 Conférence de La Haye, Étude sur la filiation juridique..., cit., p. 80, párrafo 167.

72 Ibídem, p. 81, párrafo 167. 
Esta revista forma parte del acervo de la Biblioteca Jurídica Virtual del Instituto de Investigaciones Jurídicas de la UNAM

nalidad austríaca por filiación, a un niño nacido en Estados Unidos como consecuencia de una GS. Los padres intencionales eran una pareja austroitaliana, en la que la madre intencional era austríaca. El fundamento fue el siguiente: la ley austríaca que prohíbe la gestación por sustitución no es de orden público, en el sentido de que no protege derechos fundamentales, y el no reconocimiento afectaría el interés superior del menor. En efecto, se impondría la calidad de madre jurídica a la madre portadora, a pesar de no ser la madre genética, ni la madre del niño según la ley estadounidense.

Finalmente, una tendencia más, muy restrictiva, se ha registrado en la jurisprudencia de la Corte de Casación de Francia. ${ }^{73}$ En varios casos resueltos durante 2011, ${ }^{74}$ el tribunal galo decidió que había que negar la transcripción en los registros de estado civil franceses, de actas de nacimiento extranjeras que designaban a los padres de intención como padres jurídicos de niños nacidos en el extranjero luego de acuerdos de GST. Estos casos llegaron a la jurisdicción europea competente, que unos años después condenó a Francia. Veámoslo en el siguiente apartado.

\section{Criterios del Tribunal Europeo de Derechos Humanos}

El Tribunal Europeo de Derechos Humanos (TEDH) resolvió los casos Menesson c. Francia y Labasse c. Francia el 26 de junio de 2014.

En cuanto a los antecedentes, en ambos casos Francia (como Estado de recepción) se había negado a reconocer la existencia de un vínculo jurídico entre los niños nacidos en Estados Unidos luego de sendas GS y sus respectivos padres intencionales, con quienes había lazos genéticos.

ElTEDH condenó a Francia por violación del artículo 8o. de la Convención Europea de Derechos Humanos (CEDH), que consagra el derecho de los niños al respeto de su vida privada.

En su fallo, el TEDH destacó que:

73 Ibídem, p. 81, párrafo 169.

74 Corte de Casación, primera sala civil, sentencias núm. 369, 370 y 371 del 6 de abril de 2011, https: / /www.courdecassation.fr/ (último acceso: 11 de mayo de 2015). Dos de estos casos llegaron al Tribunal Europeo de Derechos Humanos: Mennesson y otros c. Francia (asunto 65192/11) y Labasse y otros c. Francia (65941/11), http://curia.europa.eu/jcms/jcms/j_6/ (último acceso: 11 de mayo de 2015). Ambos fueron resueltos por dicho tribunal europeo el 26 de junio de 2014. Véase el apartado siguiente. 
Esta revista forma parte del acervo de la Biblioteca Jurídica Virtual del Instituto de Investigaciones Jurídicas de la UNAM

1) el derecho francés impedía absolutamente el establecimiento de un vínculo jurídico entre el niño y el padre intencional en Francia, además de impedir la transcripción del acta extranjera en el registro francés;

2) el padre intencional, en ambos casos, era el padre genético;

3) el derecho al respeto de la vida privada "exige que cada uno pueda establecer los detalles de su identidad de ser humano, lo que incluye su filiación";

4) el respeto al interés superior de los menores debe guiar toda decisión acerca de ellos.

Poco más de medio año después, el TEDH volvió a pronunciarse sobre un caso que involucraba GS, a pesar de que algunos elementos fácticos diferían de los casos franceses. Se trata del asunto Paradiso et Campanelli c. Italia, resuelto el 27 de enero de 2015..$^{75}$ En esta causa elTEDH también condenó al país demandado, acogiendo las pretensiones de los actores, que alegaban violación del artículo 8o. de la CEDH. En este caso, un matrimonio heterosexual italiano que tenía dificultades para realizar una fecundación in vitro, decidió contratar una GST con una mujer rusa en Rusia, mediante una agencia. Todo el material genético utilizado provenía de la pareja que, por lo tanto, reunía las cualidades de padres intencionales y de padres genéticos. El matrimonio le reclamó al Estado italiano la ausencia de reconocimiento y transcripción de la filiación en el registro civil de Italia, así como la decisión de separar al niño de los padres intencionales y de someterlo a un proceso de adopción en Italia que derivaría en la adopción por parte de otras personas.

ElTEDH analizó si se había vulnerado el derecho a la vida familiar y privada de los padres intencionales. Consideró que efectivamente hubo "vida familiar" entre el niño nacido en Rusia y el matrimonio de padres intencionales, ya que habían convivido durante al menos seis meses. Asimismo, estimó que de todas maneras también hubo "vida privada" entre ellos. Determinó que el artículo 8o. CEDH protege tanto una como la otra y que ambas habían sido vulneradas en este caso. Adicionalmente, destacó que es necesario que un niño no se encuentre en situación de desventaja por el hecho de haber sido traído al mundo por una madre portadora.

75 TEDH, asunto núm. 25358, http://curia.europa.eu/jcms/jcms/j_6/ (último acceso: 11 de mayo de 2015). 
Pensamos que con estas tres decisiones, el TEDH va marcando un rumbo a los Estados miembros de la Unión Europea, hacia actitud de mayor apertura y flexibilidad con respecto a la GST y sus efectos en los Estados de recepción.

\section{De CARA Al Futuro}

La GST es un fenómeno que existe, es cada vez más frecuente en la vida real y genera serios problemas jurídicos, muchos de los cuales han sido analizados en el desarrollo de este artículo. Estimamos que la comunidad jurídica no debe hacer caso omiso de esta nueva realidad sino, por el contrario, involucrarse directamente en la misma y procurar establecer allí cierto orden, de modo que los intereses de los sujetos intervinientes no resulten lesionados. Requiere especial consideración el interés superior del menor que nace en el contexto de una GST. En efecto, para prevenir el surgimiento de conflictos en torno al estatus jurídico de los niños nacidos como consecuencia de una GST y de sus padres intencionales, así como para solucionar los diferendos que de todas maneras llegaran a presentarse, es preciso contar con una regulación, preferentemente internacional.

La Conferencia de La Haya ha venido trabajando en este sentido. De hecho, considera que la GST es un tema prioritario en su agenda. Está previsto continuar estudiándolo, a fin de proponer una regulación apropiada, que pueda ser aceptada por un gran número de Estados. Una de las cuestiones pendientes de definición es la elección de la técnica de codificación internacional a emplear. Si bien este aspecto podría parecer meramente formal, resultará clave para el impacto que el nuevo (futuro) instrumento tendrá en la práctica.

La existencia de un cuerpo sistemático de normas de fuente internacional, sea de hard law o de soft law, facilitaría la adopción de criterios uniformes en el ámbito de los diferentes sistemas jurídicos nacionales y la realización de la justicia material en casos concretos. De esta manera, resultarían protegidos los intereses de las personas físicas involucradas en asuntos de GST y especialmente los de los menores, que son los únicos que no han elegido voluntariamente encontrarse envueltos en un entramado jurídico tan complejo. 
Esta revista forma parte del acervo de la Biblioteca Jurídica Virtual del Instituto de Investigaciones Jurídicas de la UNAM

\section{BIBLIOGRAFíA}

BRENA SESMA, Ingrid (coord.), "La gestación subrogada. ¿Una nueva figura del derecho de familia?", Reproducción asistida, México, UNAM, Instituto de Investigaciones Jurídicas, 2012. http://biblio.juridicas.unam.mx / libros/7/3155/10.pdf.

, "La maternidad subrogada ¿es suficiente la legislación civil vigente para regularla?", Revista de Derecho Privado, núm. 23, 2009.

Clavería GonzÁlvez, Luis Humberto, "Las categorías negóciales y su adaptación en función de la reproducción”, en La filiación a finales del S. $X X$ : problemática planteada por los avances científicos en materia de reproducción humana, Madrid, Trivium, 1988.

Conférence de La Haye de Droit International Privé, Affaires Générales et Politique, Étude sur la filiation juridique et questions découlant des conventions de maternité de substitution à caractère international, Doc. Prél. núm. 3C (L'Étude), marzo 2014, disponible en http: / /www.hcch. net/upload/wop/gap2015pd03c_fr.pdf.

Conférence de La Haye de Droit International Privé, Affaires Générales et Politique, Opportunité et possibilité de poursuivre les travaux menés dans le cadre du projet filiation / maternité de substitution, Doc prél. $N^{o} 3 \mathrm{~B}$, Annexe A - Glossaire mis à jour, abril de 2014, http://www.hcch.net/index_ fr.php?act $=$ text. display\&tid $=178$.

Conférence de La Haye de Droit International Privé, Affaires Générales et Politique, Étude sur la filiation juridique et questions découlant des conventions de maternité de substitution à caractère international, Doc. Prél. $\mathrm{N}^{\circ} 3 \mathrm{C}$ (L'Étude), marzo 2014, disponible en http: / / www.hcch.net / upload/wop/gap2015pd03c_fr.pdf.

Convenio que suprime la exigencia de legalización de los documentos públicos extranjeros, La Haya, 5 de octubre de 1961. Texto, estado actual e información adicional, http: / / www.hcch.net/index_es.php?act=conventions. text\&cid $=41$.

GONZÁLEZ MARTÍN, Nuria, "Maternidad subrogada y adopción internacional”, en BREnA SESMA, I. (coord.), "La gestación subrogada. ¿Una nueva figura del derecho de familia?”, Reproducción asistida, México, UNAM, Instituto de Investigaciones Jurídicas, 2012, http: / / biblio.juridicas. unam. $m x /$ libros/7/3155/11.pdf. 
Esta revista forma parte del acervo de la Biblioteca Jurídica Virtual del Instituto de Investigaciones Jurídicas de la UNAM

Gruenbaum, Daniel, "Foreign Surrogate Motherhood: Mater Semper Certa Erat", American Journal of Comparative Law, vol. 60, 2012.

Holt, Kyle Lee, "Hoosier Mother?: Indiana’s Inconsistent Surrogacy Law", Valparaíso University Law Review, núm. 48, 2014.

International Social Services. Boletín Mensual, Número Especial "Gestación subrogada de carácter internacional y derechos del niño”, núm. 174, Julio/Agosto 2013. www.iss-ssi.org.

LAMM, Eleonora, "Gestación por sustitución”, InDret Revista para el Análisis del Derecho, núm. 3, 2012, http://www.indret.com/pdf/909_es.pdf.

- Gestación por sustitución. Ni maternidad subrogada ni alquiler de vientres, Barcelona, Universidad de Barcelona, 2013.

MÉNDEZ Zambrano, Maritza, "La reproducción asistida", en GUERRA HeRnÁndeZ, Víctor Hugo et al. (coord.), Derecho familiar internacional. Metodología para su estudio. Homenaje a Haydée Barrios, Medellín, Biblioteca Jurídica Diké-Universidad del Rosario, 2014

Observación General núm. 14 del Comité de los Derechos del Niños sobre el derecho del niño a que su interés superior sea una consideración primordial. Aprobado por el Comité el 29 de mayo de 2013. El Comité establece que el interés superior del niño debe ser el factor determinante, es decir, no simplemente "una consideración primordial" sino "la consideración primordial". http: / / www2.ohchr.org/english.

Organización Mundial de la Salud, http://www.who.int/reproductivehealth/ topics/infertility/definitions/en/.

PENG, Lina, "Surrogate Mothers: An Exploration of the Empirical and the Normative", American University Journal of Gender, Social Policy \& The Law, núm. 21, 2013.

Pereznieto Castro, Leonel y Silva Silva, Jorge Alberto, Derecho internacional privado. Parte especial, 2a. ed., México, Oxford University Press, 2007.

PetiTfils, Charlotte y MuÑoz Sastre, María Teresa, "French Layperson's Views on Surrogate Motherhood: an Exploratory Study", Psicológica, núm. 35, 2014.

Questionnaire on the Private International Law Issues Surrounding the Status of Children, including Issues arising from International Surrogacy Arrangements, http: / / www.hcch.net/upload/wop/gap2014pd3fr.pdf.

Respuesta de Alemania a la pregunta 31 del Questionnaire on the Private International Law Issues Surrounding the Status of Children, including Issues arising 
Esta revista forma parte del acervo de la Biblioteca Jurídica Virtual del Instituto de Investigaciones Jurídicas de la UNAM

from International Surrogacy Arrangements, http://www.hcch.net/upload/ wop/gap2014pd3de.pdf.

Respuesta de Colombia a la pregunta 24 del Questionnaire on the Private International Law Issues Surrounding the Status of Children, including Issues arising from International Surrogacy Arrangements, http://www.hcch.net/ upload/wop/gap2014pd3co.pdf.

Respuesta de Francia a la pregunta 24 del Questionnaire on the Private International Law Issues Surrounding the Status of Children, including Issues arising from International Surrogacy Arrangements, http://www.hcch.net/upload/ wop/gap2014pd3fr.pdf.

RODRÍGUEZ LÓPEZ, Dina, "Nuevas técnicas de reproducción humana. El útero como objeto del contrato", Revista de Derecho Privado. Nueva Serie, núm. 11, mayo-agosto de 2005.

RODRÍGUEZ MARTíNEZ, Eli, "Los contratos internacionales sobre maternidad subrogada. Un vistazo rápido al derecho comparado”, Revista Derecho en Libertad, núm. 13, 2014, http://www.flm.edu.mx/pdf/revista/no13/ Derecho13-Arti11.pdf.

RodríGueZ-Yong, Camilo A. y MartíneZ-Muñoz, Karol Ximena, "El contrato de maternidad subrogada: la experiencia estadounidense”, Revista de Derecho (Valdivia), vol. XXXV, núm. 2, 2012.

RubajA, Nieve, "El derecho internacional privado al servicio de los derechos fundamentales de los niños nacidos por el empleo de la gestación por sustitución en el extranjero", en MORENO RODRíGUEZ, José Antonio y Lima MARQUeS, Claudia (coords.), Los servicios en el derecho internacional privado. Jornadas de la ASADIP 2014, Porto Alegre, Gráfica Editora, 2014.

SPIVACK, Carla, "The Law of Surrogate Motherhood in the United States", American Journal of Comparative Law, vol. 60, núm. 58, 2010.

Trimmings, Katarina y BeAumOnT, Paul, "International Surrogacy Arrangements: an Urgent Need for Legal Regulation at the International Level”, Journal of Private International Law, vol. 7, núm. 3, 2011.

VINCENT y AfTANDILIAN, "Liberation or Exploitation: Commercial Surrogacy and the Indian Surrogate”, Suffolk Transnational Law Review, núm 36, 2013. 
Esta revista forma parte del acervo de la Biblioteca Jurídica Virtual del Instituto de Investigaciones Jurídicas de la UNAM

Casos citados

Alemania, Tribunal Federal alemán, sentencia del 10 de diciembre de 2014. Resumen y comentario en inglés en: Reis, Dina, “German Federal Court of Justice on Surrogacy and German Public Policy", posteado por Jan Von Hein en el blog Conflictoflaws.net, 4 de marzo de 2015, http: / / conflictoflaws.net/2015/german-federal-court-of-justice-on-surrogacy-andgerman-public-policy/.

Australia, Nueva Zelanda y Reino Unido, entre otros países. Conférence de La Haye de Droit International Privé, Affaires Générales et Politique, Étude sur la filiation juridique et questions découlant des conventions de maternité de substitution à caractère international, Doc. Prél. núm. 3C (L'Étude), marzo de 2014 http://www.hcch.net/upload/wop/ gap2015pd03c_fr.pdf.

Estados Unidos de America, Baby M. In re Baby M, 537 A.2d 1227 (N.J. 1988).

Francia, Corte de Casación, primera sala civil, sentencias núm. 369, 370 y 371 del 6 de abril de 2011, https: / /www.courdecassation.fr/.

Francia, Estrasburgo, Tribunal Europeo de Derechos Humanos, asunto $\mathrm{N}^{\circ}$ 25358, http://curia.europa.eu/jcms/jcms/j_6/.

Francia, Estrasburgo, Tribunal Europeo de Derechos Humanos: Mennesson y otros c. Francia (asunto 65192/11) y Labasse y otros c. Francia (65941/11), http://curia.europa.eu/jcms/jcms/j_6/

México, Tribunal Supremo, Pleno, Sentencia núm. 835/2013, 6 de febrero de 2014, http://www.poderjudicial.es/cgpj/es/Poder-Judicial/Tribu nal-Supremo /Jurisprudencia / Actualidad-Jurisprudencial / TS-Civil-Pleno-Desestima-recurso-de-casacion--Gestacion-por-sustitucion--Inscripcion-enel-Registro-Civil-espanol-de-la-filiacion-de-unos-menores-nacidos-tras-la-ce lebracion-de-un-contrato-de-gestacion-por-sustitucion-a-favor-de-los-padresintencionales--determinada-por-las-autoridades-de-California-con-base-en-lalegislacion-de-dicho-estado-. 